\title{
The new gendered labour of synchronisation: Temporal labour in the new world of work
}

\begin{abstract}
Research considering how time is organised has shown that women tend to carry a disproportionate burden of coordinating the schedules of their households. However, little research has considered how these gendered inequalities may manifest in the context of the shift away from 'standard' work patterns and towards variable and non-standard hours. We address this question by using interview and digital data to consider how a selection of 'ordinary' Australian young adults in heterosexual partnerships manage and coordinate their time. We contend that even for middle-class young adults with relatively high employment security, increasingly complex working arrangements are shifting existing inequalities in gendered divisions of temporal labour in ways that heighten feelings of temporal insecurity. We conceptualise our findings as part of an intensification of the existing need to schedule and manage lives that is widely felt in the so-called 'gig economy era', even by those removed from gig work proper.
\end{abstract}

Keywords: gig economy; gender; temporality; work; youth

\section{Introduction}

Changes in contemporary employment have been led by a shift towards less secure conditions. Given less attention, however, is the move away from standardised work patterns. In Australia, along with many other Western economies, the rise of nonstandard work patterns have coincided with women overtaking men in educational attainment and greatly increasing their labour force participation. While Hochschild and Machung (2003), along with several other feminist scholars, have observed the disproportionate burden that women face while balancing workforce participation with domestic and caring work - producing insights about the ways in which women are often disproportionately responsible for coordinating the plans and schedules of their household - little research has considered how such dynamics may manifest in the context of non-standard work patterns becoming more common. We draw on qualitative data from Australian couples in their late 20s to show how the rise of dual income households, coupled with the rise of nonstandard hours in paid employment, have resulted in an increasing need to schedule and manage lives and an accompanying sense of temporal precarity, even among the middle class. Indeed, these broader temporal changes may be an autonomous driver of some of the affects that are often tied to and exacerbated by precarious or gig work. We contend that the labour involved in synchronising schedules is intensifying and refiguring the gendered division of labour and that, alongside the erosion of the standard working week, is resulting in the manifestation of existing gender inequalities in new forms.

\section{'Work-life balance'}

Research on 'work-life balance' is booming in the social sciences, driven by widespread anxiety about the impacts of changing work patterns on the social fabric (Pocock et al. 2012). The scholarship has shifted from balance to 'interference' and 'integration' in the context of a blurring boundary between work and non-work (Fein et al. 2017). Researchers have focused on the so-called 'rush hour of life' in which the pressures of employment commitments and childcare demands 
collide (Craig and Powell 2011, Hewitt et al. 2012), highlighting in particularly enduring gender inequalities and the impact of these pressures on children and parents' wellbeing (Strazdins et al. 2006). Today those in this 'rush hour' are largely in their 30s-50s. Yet, Australian young adults aged 20-29 report almost as high levels of work-life 'interference' as adults aged 30-44, and higher levels than employees aged 45 and older (Pocock et al. 2012), suggesting something beyond the concrete demands of dual income families juggling care and workforce participation.

This finding becomes less surprising if we recognise that younger workforce participants are disproportionately affected by changes in the nature of employment. Recent commentary and concern about the future of work has focused on the 'gig economy', the rise of new forms of individualised contract-based employment, often dependent on large intermediaries that control the digital platform through which 'gig-work' tends to be sourced (Harris and Krueger 2015). The size of the gig economy is notoriously difficult to measure. At present no nationally representative survey collects data directly on this topic due largely to definitional challenges, meaning that sole selfemployees provide arguably the best available proxy measurement. The number of people working as 'sole self-employees' in Australia is small (especially compared to contexts such as the UK); it has remained relatively flat over the past decade and has declined since the beginning of the century, currently sitting at around 8.5 percent of employed persons (Cowling and Wooden 2018). Additionally, multiple job-holding has also decline from an already small base in the last decade, challenging the hypothesis that the growth of the gig economy is accounted for by employed individuals taking on additional work (Cowling and Wooden 2018). Casual employment rates, in contrast, account for a much higher proportion of the workforce and contract and labour hire use has grown, albeit from a small base. At present approximately 25 per cent of the Australian workforce is casual (typically defined as employees without access to leave entitlements), although again this has been largely flat since the start of the century, with much of the rapid increase taking place in the 1980s and particularly the 1990s (Gilfillan 2018).

Nearly 60 per cent of casual employees are aged 35 or under (ABS 2011). The young are clearly most affected by the growth of jobs with 'non-standard' employment conditions and relative to 'prime' aged and even older employees the already disproportionate representation of young people among those with non-standard conditions and variable working patterns has increased over the past fifteen years, even as overall levels of casual employment have remained flat (Venn et al. 2015). Higher education or an apprenticeship and multiple years of experience are often required to enter ongoing employment with standard conditions (Price et al. 2011). Both issues, casualisation and the rise of non-standard employment relations, are important shifts in the way that people are working. However, a relatively-overlooked aspect of changing employment patterns that may impact on people's sense of control is the rise of non-standard hours of work - including weekend, evening and variable hours. Differing levels of control over temporal schedules in an increasingly 24-7 economy is argued by some to be emerging as a primary dimension of inequality (Presser 2005; Goodin et al. 2008; Clauson and Gerstel 2014).

Younger employees are transitioning towards permanent contracts, albeit at a slower pace than in the past, and by their late twenties, most workforce participants are on a permanent or renewable contract (ABS 2011). However, the shift towards standard hours of work is even slower, and Australian research shows that working non-standard hours is very common for people in their 20s with likely impacts on work-life interference (Author 2013). Yet, there has been little interest in work-life interference for those in this age group, with researchers instead focused on the direct economic impacts of youth labour market conditions, such as the problem of youth underemployment. The problem of underemployment would suggest too much 'leisure' time, 
depending on the demands of any active labour market programs or job search activities. The 20s are seen as a time when leisure with a friendship group or significant other is seen as developmentally essential for 'emerging adults' but is also assumed to be easily available (Arnett 2014). Time-use data, however, does not support this. While people in their 20 s have slightly more free time than those in the 'rush hour of life', they have less free time than those aged 45-64 (Author 2015; ABS 2006).

Long hours of paid employment are only a small driver of work-life intrusions (Presser 2005; Pocock et al. 2012; Wajcman 2014). The rise of a more '24/7' economy at the end of the $20^{\text {th }}$ Century, characterised by variable and patterns of engagement, is arguably one of the most significant changes marking the lives of today's young people as different from those of previous generations (Author 2013). Some occupations (e.g. medical professions, some manufacturing) have been associated with non-standard hours long before this time but the scope of this experience expanded rapidly through the 1990s (Venn 2004). As noted, growth in some aspects of 'non-standard' work flatted out during the 2000s, at least for prime aged workers but so called 'flexible' patterns of work hour continued to increase (Venn et al. 2016) as has the blurring of work and non-work time (Gregg 2011). As Author (2012) has shown previously for young people aged 18-20, relatively individualised work patterns create new challenges for synchronising rhythms and schedules so that time can be regularly spent with significant others. It is potentially an autonomous factor behind feelings of lack of control and insecurity that tend to be linked to other changes, like casual employment and the gig economy. Yet this significant change in the way young adults are working has been largely overlooked in conceptualisations of the gig-economy era. Many far outside the gig-economy may have hours that tend towards gig-economy patterns, with varying flexibility, which they need to coordinate with significant others. Studying the direct economic impacts of changes in the youth labour market is important, but the neglect of the impact of shifting work patterns on work-life interference is unjustified. The surprising levels of work-life interference claimed by those in their 20s suggests a puzzle through which some of the ways insecure work might be affecting lives beyond work can be unravelled. It is this puzzle that we begin to address in this paper, focusing specifically on the worklife experiences of people in their late 20s in intimate relationships (all heterosexual), most without children and largely middle class. Specifically, we draw on the claim that synchronising lives with others demands new efforts in an increasingly 24/7 economy to consider how this work is managed collectively in couples, showing that it has effects that resonate with some claims about the gig economy or the impact of insecure work, but potentially impacting a broader cohort of employees.

In order to conceptualise the impact of insecure employment and non-standard hours on young adults we turn to the work of Berlant (2011) who proposes that contemporary individuals are navigating an increasingly precarious and incoherent work situation by creating modes of adjustment for getting by that are maintained by an affective structure of 'cruel optimism' that a better life is being built over time in the face of growing evidence to the contrary. Her work has been used to understand the subjective and affective side of the rise of insecure and gig work; how individuals maintain investment in one-sided and damaging employment relationships through notions of 'hustle', side-gigs, and building entrepreneurial and transferable skills. There is, however, one source of optimism that Berlant holds on to as a potentially sustaining (not cruel) fantasy of self-made stability in an unstable world: intimate connection, the possibility of reciprocity and care available through a significant relationship. This allows individuals to proceed together, to have 'adventures and [be] in the impasse together' in a way that allows them to carry on in a fragile world (Berlant 2011: 266). It is only through others that we can refuse to be worn out by cruel optimism. Berlant, working within a feminist and queer frame is not naïve about the challenges to and limits of significant relationships. Her account of the sustaining potential of significant relationships in contexts of uncertainty underpins our own aim 
of interrogating the temporal and structural foundations of these relationships. Specifically, by addressing the gender dynamics at play within these relationships in the context of increasingly complex temporal structures we consider whether the fantasy of reciprocity and adventures with a significant other may itself remain too optimistic.

\section{Gender, work and temporality}

Changing work patterns must be understood with a lens on gender. It is already known that the scheduling work that supports relationships is highly gendered. There are many factors at play in the creation of gender inequality in the workforce, including the pay gap, but the temporal structure of paid employment is one of the more significant (Goldin 2014). The relative flexibility of higher education works well for many young women (Author 2017), while the rise of part time work and work outside the standard 9-5 Monday to Friday pattern suggests the possibility for new 'flexibility' in the mixing of paid employment and other responsibilities. Yet, despite some noteworthy policy changes to improve flexibility for employees, it often comes with a pay penalty and a negative impact on career progression. The 'male breadwinner model' no longer holds with the rise of dual income couples and families, but the norm still shapes many aspects of paid employment, including the temporal demands (Nockolds 2017).

Many feminist theorists of time have distinguished between men and women's time to highlight that prevalent conceptions of temporality are based on men's lives, emphasising the ways in which the institutions and practices through which time is experienced produce gender differences and inequalities (Davies 1990; Bryson 2007).The use of a temporal lens of this type helps to highlight some of the limitations of current provisions of and access to flexible work arrangements, particularly for gender equality, showing how the continuing 'male-breadwinner model' becomes even more problematic given the rise of non-standard work patterns (Nockolds 2017).

Seemingly as a result of the continuity of the 'male-breadwinner model' young women in Australia who are in the prime of their working lives often face personal responsibility for managing incompatible structural (and temporal) demands (Author 2017). Although the normality and increasing necessity of dual-income households has been accompanied by an increase in women's participation in employment, it has not entirely negated the equation of men with career-based pursuits and women with the domestic sphere. Indeed, Hochschild and Machung (2003) have famously argued that women's participation in the workforce, when combined with the expectation that they will continue to fulfil domestic duties, has led to the creation of a 'second shift' comprised of domestic and care-based work that is undertaken when women leave their paid occupation. A number of scholars have also claimed that the ongoing expectation that women will complete this type of labour (even among contemporary youth) is coupled with the expectation that they will take on temporal responsibilities in this sphere. For instance, women often find themselves responsible for managing not only their own time, but also for coordinating the plans and schedules of their entire household (Thompson 1996; Arendell 2001; Daly 2001; Hochschild and Machung 2003).The double burden of employment and domestic responsibilities that is experienced by women, and the constraints that this places upon their time, also appear to be accompanied by an expectation that they will coordinate between these spheres and therefore take responsibility for the overarching architecture of their family's plans, while men are more often left to simply navigate their working lives.

The current scholarship on work-life interference leaves unexplained the concern for work-life interference expressed by younger cohorts. Hockey (2009) argues that although contemporary young adults' lives often appear to be relatively unshackled from gender role expectations, this is 
often disrupted by childbearing. Yet, Author (2017) suggest that the effects of gender continue to have an impact before parenthood. Many of the young adults who report work-life interference are without caring responsibilities, but they do tend to have work-lives that are experienced as unpredictable and insecure, even by those who might seem objectively to have security over and high autonomy within their employment. We address this by turning now to data concerning the temporal experiences of heterosexual couples in their late $20 \mathrm{~s}$.

\section{Method}

The data presented in this article are drawn from a 2017 study embedded in the [name of study], a larger mixed-methods longitudinal panel study of young adulthood in Australia. The participants in this part of the study were from the Year 12 school leaving cohort of 2006 and were recruited into the study in 2005 or 2006. They were aged 28-29 in 2017 when the data for this study were collected. The study involved the collection of digital data from a mobile phone app followed by indepth interviews, all conducted by the two authors of this article. While selecting participants to recruit from the broader [name of study] sample we focused on those who had experiences of nonstandard hours. We also asked these participants to invite a significant other who they tried to spend time with in a given week to take part in the study, with the aim of understanding not only their own lives, but how they intersected with the lives of those around them. A total of 53 participants took part in the study. This included 37 existing [name of study] participants and 16 significant others, meaning that just under half of the participants recruited someone into the study. The significant others included 11 heterosexual couples, three housemates, one friend/workmate and one sibling.

We focus on 11 heterosexual couples in this article, drawing on the app-based data and individual interviews. While the 11 existing [name of study] participants were all tertiary educated and working in professional positions, their partners (four married and seven de facto) exhibited a greater degree of diversity. Seven were tertiary educated, while three had undertaken apprenticeships or vocational education, and one had undertaken no post-secondary education. Seven worked in professional positions, while two worked in managerial roles, and two in trades. All but one of the male participants worked at least full time, with two also working a second job. Four of the couples were parents, seven of the female participants worked full time, while the other four (all parents) worked part time, with one on maternity leave at the time of the interview. Nine of the couples lived in a capital city (Melbourne, Sydney or Canberra), while one lived in a large regional city, and one in a small regional town. However, the couples' location did not appear to have an overt impact on their management and experience of time.

The digital mode of data collection involved using a mobile phone-based app and was conceived as a way of gaining insight into how the participants balanced different commitments including paid work and relationship demands. We used an app named Slack which the participants downloaded onto their mobile phones and asked the participants to post text, photos and videos about what they were doing and/or how they were feeling a minimum of 5 times a day over a weeklong period. We provided a list of topics for participants to consider (including activities such as paid work, caring, leisure time, socialising, etc.) but we did not dictate the form posts should take. We regularly prompted them for further detail with follow up texts when they shared short or relevant posts. This mode of data collection was essentially intended to function as a qualitative time use diary, and allowed us to gain insight into the participants' day-to-day lives.

The weeklong digital data collection was followed by a one-on-one interview which averaged 60-90 minutes. The interview schedule, much like the prompts used for the digital mode of data collection, 
included a broad range of questions which sought to gain understanding of the intersecting commitments that formed the participants' lives. The first part of the interview was based on posts, selecting 3-4 of the participant's posts and either asking them questions about them or asking them to elaborate upon them. These posts were generally selected because they touched upon the key areas of interest to the project, such as the participant's experience of balancing work with other aspects of their life. This provided a successful entry-point into the interview, allowing us to discuss everyday experiences in a way that set the tone of the subsequent discussion. Specifically, the rapport and knowledge (on the part of the interviewer) that was developed over the course of the digital data collection resulted in interview data that were based more on stories and discussions of specific experiences than on more general explanations, allowing us insight into the participants everyday lives and routines that can be difficult to achieve in the context of research interviews.

The data were initially analysed using a priori coding based on the interview questions, which allowed us to identify commonalities and differences between the participants' responses. A closer round of thematic open coding then allowed us to identify patterns that were reflected across various parts of their lives (e.g. work, leisure, family life). At this stage we focused on the formation, use and experience of time, routines and scheduling. This step was important for gaining insight into how the participants organised and coordinated their time. It also allowed us to incorporate the app posts into the analysis. In so doing we were able to compare the participants' reflections on their scheduling and organisation of time with some of the in-the-moment realities that they had posted about and, in some cases, uncover points of difference between their perceptions and experiences. While we initially focused on schedules and time use due to an interest in work-life interference and leisure time, it quickly became apparent that gendered dynamics were at play not only in the use of the participants' time, but in the organisation of it. Moreover, the gendered dynamics that we observed in the organisation of time directly informed the use of time. Put simply, the individual who managed scheduling and coordination (women in this study) generally took primary responsibility for ensuring that necessary tasks (e.g. organising childcare) were completed. Inequalities in labour and leisure stemmed from, and were even naturalised by, the gendered nature of scheduling and its intensification, and this informed our focus on this area as a key aspect of wider gender inequalities in intimate relationships.

\section{Findings and discussion}

Although the sample whom we draw upon in this paper present one major point of difference - four were parents, while the remaining seven were not - they also reflected many notable similarities. The most overt was in relation to their experience of work. Although our participants were aged 2829 and largely working within professional roles, suggesting that it would be likely for them to have a standard 9-5 Monday-Friday work week, while analysing the qualitative time-use data it was clear that they nevertheless often worked non-standard hours due to overtime for some and work schedules for others. Additionally, while the four couples with children reported that becoming parents represented a significant shift in the temporal organisation of their lives, which initially suggested to us that they needed to be treated with a degree of analytical separation from those without children, closer examination revealed that the foundation for several of the tendencies reflected in the temporal management of these couples appeared to be present also for couples without children. The tendencies that we observed across the sample related to the participants' coordination and management of time are now each discussed in turn.

\section{The distribution of scheduling and coordination labour}


When the participants were asked who, within the couple, was responsible for finding or planning time together they generally stated that this was either distributed evenly or slanted slightly towards one partner. However, closer examination of the participants' specific schedules, and the ways in which they were managed (facilitated in large part by the qualitative time use data from the app) demonstrated that the practices through which an 'egalitarian split' in organising and managing shared time was achieved were commonly implemented, managed and maintained by the female partner.

This tendency was evident for Samantha, an accountant, and her de facto partner Jacob, a web developer. Both worked full time, undertook voluntary work, and belonged to multiple clubs and professional associations, and on top of this Jacob ran his own side business, meaning that their hours of work typically exceeded a conventional full time schedule, and that their work often took place outside of 9-5 hours. Their schedules were therefore full and complex - something that they each attributed to their desire for professional development and advancement. This desire appeared to be shaped by the insecure nature of their work - Samantha in particular was employed on a 12month fixed-term contract to cover another staff member's maternity leave and did not have a position lined up to correspond with the end of this contract. Samantha and Jacob appeared to have a relatively egalitarian split with regards to managing their schedules and finding time together. For instance, Samantha reported that:

We both contribute ideas about what we wanna do, and then we plan out the time to do some, most of them. Now, every Sunday night we have a meeting and we will discuss all what our weeks look like, and then what we are going to do on Friday night... We both share ideas.

However, when asked how long they had this routine, Samantha told us it had only been in place for approximately a month at her instigation in response to her frustrations with not having enough time together. Prior to this arrangement the couple had used a shared calendar-based mobile phone app which allowed them to see each other's schedules. However, Samantha found that Jacob did not always keep his calendar updated, and that for this reason she often did not know what he was doing or where he was:

Sometimes like in the past I was like where are you? And I would never get a reply, I would get so upset. We share the calendars together, and I could see what he is on tonight, but if we don't update our calendars on time we would just lose track of each other. So that's why sometimes I got- I got a bit cranky and was like "why don't you update your calendar?"

Jacob echoed Samantha's narrative, reporting that she was frustrated with his failure to update his calendar and that their coordination of time together had recently improved. However, he did not attribute this to their Sunday night planning and increased diligence with recording his plans. Rather, he attributed it to weekly meetings with a life coach:

So, I meet with [coach] on a Monday night and plan out what my priorities are over the next week. Put that into my calendar, and then I'Il have a bit of an accountability check of how I went the previous week. As part of the goals, I'll put in not just work stuff but business, relationship, finance, career progression, all the things that I think are important.

When asked why he sought coaching Jacob stated:

I went to her and said, "Look, I want help with balancing everything," because I knew that, in theory, that I did want to have a more balanced life. 
Ultimately, while Samantha and Jacob each contributed to managing their shared time and reported that the work of scheduling time together was relatively evenly distributed, when these practices were interrogated further a complex gender division and inequality emerged. Specifically, Samantha originally instigated calendar sharing and then, when that was not successful, the Sunday night planning. Jacob complied with these plans, but essentially outsourced his scheduling when Samantha expressed dissatisfaction with his original efforts. Importantly, the tendency for men to outsource the minutia of planning labour was reflected throughout the sample. However, rather than outsourcing to a life coach, many of the men instead appeared to essentially 'outsource' to their partner. For instance, when Carla, a self-employed hairdresser who worked from home and routinely worked evenings, was asked who organised social events for herself and her husband Nathan, a property valuer with whom she shared two children, she initially stated that Nathan was more proactive about planning social events:

[husband] is a lot more, "Let's go do this", where I'm more a, "Can't we just stay at home and spend time together?". And [Nathan] is more like ... he'll say, "Let's invite some people over for tea", and I'm like, "I've literally just finished work. The last thing I want to do is deal with more people".

However, it appeared that although Nathan was more likely to suggest social events, the labour of actualising these events - inviting family and friends, cooking - generally fell to Carla. Additionally, Carla found herself disproportionately responsible for managing their children's social and extra curricula commitments. While Jacob and Samantha and Nathan and Carla's lives looked markedly different, they each discussed planning and organisation as a shared task in a way that obscured the fact that the 'work' of establishing a planning regime or actualising plans fell disproportionately to women.

This tendency was indeed evident in a more overt form for Abigail, an occupational therapist, and her husband Simon, a public servant, who had three children. Abigail and Simon had busy and complex schedules. Simon worked full time, while Abigail mixed tertiary study with full time work while taking primary responsibility for the care of their three children, one of whom had additional needs, necessitating a large volume of specialist appointments. While Simon and Abigail both officially worked 9-5 hours, they each typically used evenings to catch up on work and, in Abigail's case, study. Additionally, while they lived with Abigail's father who undertook a caring role for the children, this caring was negotiated by Abigail. When asked who took responsibility for organising the family's time Simon responded:

I'm probably more of the organiser but that's partly because of the role I have at work now, it comes a bit more naturally, and because [Abigail] is always busy with, you know, doing her work or Uni or the kids or, so yeah I think I've taken on more of that role.

However, Simon appeared to view being the 'organiser' as determining events to be attended. This view contrasted with Abigail's own views. While she acknowledged that Simon chose activities to undertake, she nevertheless stated that she was responsible for the scheduling involved in making them possible:

I do all the scheduling as you might have picked up on. [Simon] doesn't do much of that. Um, but yeah. So I take care of that, I suppose. And that helps us to run things smoothly.

Simon's reference to his workplace role as a manager, and the way in which this role - and with it the delegation of tasks - came naturally to him in his personal life as well, was exemplified in his 
reflections on the impact of recently losing his driver's licence on work-life balance. He saw it as having a positive impact while also making planning easier for Abigail:

Since losing my licence and doing the public transport it's going a lot better, which I mentioned earlier. I'd say from August last year to maybe July this year it was heavily leaning towards, you know, towards work instead of life side. Since getting the train and stuff to work has definitely evened up a lot more. I know when I nearly get home that makes it easier for [Abigail] to plan what dinner is and all that kind of stuff and if she's working I'm home at a certain time to watch the kids, so that's definitely helped in that aspect.

However, Abigail's digital posts illustrate that dropping off and picking up Simon from the train station daily added a new task into an already complex schedule, one that needed to be coordinated with her own work, the schedules of their three children, domestic tasks such as preparing dinner, and coordinating with her father when necessary. Evidently, while this development rendered Simon's schedule more predictable and facilitated additional time with the children, it added to Abigail's coordination work, which was not acknowledged by Simon in his posts or subsequent interview.

\section{Freeing up time for one's partner}

In addition to presenting the work of planning their time as relatively equally shared, the couples more broadly viewed their relationship as a partnership, reporting a willingness to cover more of the household work when necessary so that their partner could meet other commitments. However, this manifest in markedly different ways for the men and women. For instance, David, an online learning program designer who worked in an online teaching role in addition to his full-time job, reported that he struggled to keep up with his workload and routinely worked in the evenings to meet the demands of his second job, and that as a result the burden of domestic tasks was unevenly taken up by his de-facto partner Jessica, an administrator who worked more traditional 9-5 hours. While discussing this David stated:

Work has absolutely consumed me. I feel awful because I'm not able to do my fair share. So, I come home, and partner is super supportive and does I suppose, has been doing the vast majority of cooking because I have to get on computer and start answering student's queries. I just don't have that time.

The young men were doing some domestic tasks and did not suggest that they should not. However, their naturalisation of women as managers of time also appeared to result in a comparatively heavy burden of both emotion work (in the form of alleviating their partner's guilt) and domestic labour. The same pattern was visible in relation to leisure activities. For instance, Nathan's wife Carla supported his hunting trips:

Interviewer: So, so how does your partner feel about the uh, hunting sort of stuff as well? Is she on board?

Nathan: As long as it doesn't affect what I need to do around the house to help her out. I mean, it's a partnership at home. You've each got to sort of chip in in your own way. So as long as I'm pulling my fair share around home she's supportive of me going and doing those other things. She knows what they mean to me and, you know, she understands the reasons why I go do it, and the enjoyment.

While Carla also made time for a leisure pursuit, playing social netball for a local club, the scheduling work involved in actualising this activity was comparatively more complex. Specifically, although 
Nathan looked after their children while she went to netball, he did not take over the childcare and coordination work preceding this, meaning that although Carla was able to attend netball she found it 'hard' to do so:

While I was playing netball, it was hard because I would literally go from swimming, drop [daughter] home to [Nathan], and then go straight to netball. But then sometimes netball would be quite late, so it would be an 8:30 game. So you don't get home til 10:00.

Notably, Carla's netball games signified a markedly different time commitment when compared to Nathan's hunting trips, which typically involved long periods of time (several hours, and in some cases an overnight stay) away from the family and outside of mobile phone coverage.

Indeed, family were often called on to help to facilitate men's leisure pursuits, and these pursuits were often protracted in nature. As an extreme example, Andrew, a public servant, discussed an instance when, the weekend following the birth of their son, his wife Fiona, a teacher who was on maternity leave at the time of data collection, supported his plans to travel interstate to watch the Australian Football League (AFL) Grand Final. He told us this was facilitated by Fiona asking her family for additional support over the weekend.

Fiona's been absolutely amazing. Three, four weeks ago when the AFL Grand Final was on I planned with my punters club [group of friends who socialise around sports gambling] to go to the Melbourne to the AFL Grand Final... And she's like "Yeah, yeah, it's fine."

While the male partners in each of these scenarios were appreciative of their wives' support in pursuing their chosen leisure activities, and showed some awareness that pursuing these activities was not always possible, it nevertheless appeared that their partners rarely made similar requests of this type, particularly if it involved being away for more than a very brief window of time. This was especially apparent for the couples who had children, but not absent in other couples, presumably because those without children are typically less constrained in pursuing independent forms of leisure.

\section{Preferences and predispositions}

As we saw above, the young men were sometimes apologetic for times they felt they were asking a lot of their partners. However, in general the common deviations from the professed norm of a shared responsibly for this scheduling and time-based work were framed as a result of preferences and predispositions. For instance, while discussing their use of a shared calendar app Bruce, a broadcaster, told us that his wife Deborah, a doctor, took on the greater share of scheduling labour due to her superior organisation:

She's definitely a lot more organised than I am. Um, but she's the one that insisted on us having a calendar that's in both of our phones, so that if she has something, it pops up in mine and vice versa. You know, a lot of the things that we do end up being things organised through her friends or her family, but, um, I still feel like we both try and do things.

Views of this type were also reflected by Deborah:

I probably do most of the cooking, but that's mainly because I am home first at night time for dinners and things like that.

The labour that Deborah typically undertook in organising their schedules is particularly salient as Deborah and Bruce each worked non-standard (and in many cases conflicting) hours. Deborah also attributed the fact that she often cleaned in-between other tasks to her being 'a bit of a neat freak'. 
Notably, the attribution of uneven amounts of work to aptitude or preference represented the second tendency that was evident across both the childless couples and those who had children. For instance, while discussing the organisation of schedules and distribution of domestic labour Abigail stated:

The general day-to-day running of our family. That's sort of like what I handle. You know, [Simon] helps out where he can. And I just pretty much tell everybody where they need to be... So, that's just my personality. I think that was never something that we decided. It was just how it kind of fell into place.

The participants reported a relatively equal sharing of the work of managing the complex schedules of their lives. Yet in the detail of the posts and interviews it was clear that for these participants, the organisation of time has continued to unfold through a seeming delineation between men and women's time, even as both partners are heavily invested in paid employment (Davies 1990; Bryson 2007). This was not completely naturalised, with the women presenting some exasperation at their partner's lack of organisation and some of the men apologetic about the inequality. Yet, the participants rarely presented the differences within their relationships to us directly in gendered terms, framing them instead in terms of choice and preference, and in so doing brushing over the structured gendering of the work of managing the synchronisation of at least two complex schedules.

\section{Conclusion}

The male-breadwinner model no longer fits with the reality of our participants' lives (Bryson 2007). In all but one of the partnerships discussed here both members participated in the workforce (with one participant on maternity leave). Yet the model seems to live on in the gender structure that guides the division of synchronising work. While greater flexibility in organising work time in principle can benefit individuals and broader gender equity in the context of employment, particularly if this flexibility is legitimately on employees' terms, discussions of flexibility often overlook the impact of greater structural variability in the temporalities of employment. Presser (2005), in a US context has shown that nonstandard employment schedules differ in their impact by gender. As well as a continuing unequal division of household labour, the effects of variable work and the juggling it brings tends to fall primarily on women. Its effects are also more significant for the poor and those with the least autonomy over their time. Indeed, control over temporal unpredictability is a key axis of contemporary inequality (Goodin et al. 2008; Clauson and Gerstel 2014).

In this study, we have shown that there is the added (gendered) challenge of creating synchronisation in a context pushing towards desynchronsation. There is some suggestion in these interviews of an equalisation of responsibility, or at least a sometimes-apologetic recognition from the young men that this work should be equally shared and that their partner, like them, had a complex life. Yet, this equalisation is partial and does not negate or even counteract the implicit (and naturalised) assumption that women are responsible for setting up and maintaining the routines and structures in which synchronisation work occurs. The current scholarship on work-life interference leaves unexplained the concern for work-life interference expressed by younger cohorts, even before children arrive (for those who, indeed, will have children). However, we found that many of the participants were without child-care responsibilities, but had work-lives that were experienced as unpredictable and challenging to manage. As work schedules, and indeed lives, have become increasingly complex and unpredictable, we have also shown that - within heterosexual relationships - the foundations for the type of arrangements common for couples entering 
parenthood (see Yavorsky et al. 2015) are often evident prior to (and may possibly be present to a degree in the absence of) childbearing.

Hochschild and Machung (2003) have contended that women use paid work essentially as a source of relief from the demands of their family lives, finding it offers comparably well delineated expectations and, in some cases, a greater degree of recognition. It is thus perhaps ironic that the heightened demands on individuals' time provoked by the increasingly complex schedules in the context of the new economy have positioned these young women to take up roles as 'time and motion experts' within their relationships. This creates a largely overlooked mechanism through which a sense of temporal precarity may be emerging in our shifting economy. The temporal experience of only planning from gig to gig is spreading among young adults, even for those, like many of our particiapnts, in secure employment and in the middle classes (although true 'gig work' and insecure employment surely amplify this experience). This creates tension for women as they seek to balance paid employment with the work of sustaining their relationships (whether or not they have children). This context has been called an 'unfinished revolution' (Crossley 2017), a characterisation that points to the challenge inherent in reliance on intimate relationships as a source of solidarity in a context otherwise characterised by cruel optimism (Berlant 2011). It is indeed this context that sets our findings apart from the existing literature addressing scheduling and synchronisation labour that women perform. Although much of what we have found suggests significant continuity with the past, the experiences and expectations that we have addressed nevertheless unfolded within a meaningfully different context marked by increasingly complex schedules (and lives). As such, when they are paired with the rhetoric of equality and partnership, and the naturalisation of inequalities that papers over instances that counteract this rhetoric, the manifestations of this scheduling labour presents a new way in which the practices through which time is experienced and managed produce gender differences and inequalities. Ultimately, while the participants whom we have discussed are buffered from or have essentially aged out of some of the labour market conditions (e.g. casual employment) that we discussed earlier in this paper, their experiences are significant because they suggest that non-standard hours - which are often associated with casual and insecure employment - may be part of the 'new normal' in the contemporary world of work for young people and increasingly beyond. It is on this basis that we emphasise the need to understand the impact that this development has on the lives of contemporary young adults, and the ways in which this can perpetuate and even exacerbate inequalities not just at work, but also at home.

\section{References}

ABS. (2006) 4153.0 - How Australians Use Their Time, 2006. Canberra: Australian Bureau of Statistics.

ABS. (2011) 6310.0 - Employee Earnings, Benefits and Trade Union Membership. Canberra: Australian Bureau of Statistics.

Arendell, T. (2001) 'The New Care Work of Middle Class Mothers: Managing Childrearing, Employment and Time', pp. 163-204 in K.J. Daly (ed.) Minding the Time in Family Experience: Emerging Perspectives and Issues. Oxford: Elsevier Science Ltd.

Berlant, L. (2011) Cruel Optimism. Durham: Duke University Press. 
Bryson, V. (2007) Gender and the Politics of Time: Feminist Theory and Contemporary Debates. Bristol: The Policy Press.

Clawson, D and Gerstel, N. (2014) Unequal time: Gender, class, and family in employment schedules. New York: Russell Sage Foundation.

Craig, L. and Powell, A. (2011) 'Non-standard work schedules, work-family balance and the gendered division of childcare' Work, Employment and Society, 25(2): 274-291.

Cowling, M.L. and Wooden, M. (2018) 'Self-employment and independent workers', pp. 95-102 in R. Wilkins and I. Lass (eds.) The Household, Income and Labour Dynamics in Australia Survey: Selected Findings from Waves 1 to 16. University of Melbourne: Melbourne Institute: Applied Economic \& Social Research.

Crossley, A.D. (2017) Finding feminism: Millennial activists and the unfinished gender revolution. New York: New York University Press.

Daly, K. (2001) 'Controlling Time in Families: Patterns that Sustain Gendered Work in the Home', pp. 227-249 in K. Daly (ed.) Minding the Time in Family Experience: Emerging Perspectives and Issues. Oxford: Elsevier Science Ltd.

Davies, K. (1990) Women, Time, and the Weaving of the Strands of Everyday Life. Aldershot, Brookfield: USA Gower Publishing Co.

Fein, E.C., Skinner, N. and Machin, M. A. (2017) 'Work intensification, work-life interference, stress, and well-being in Australian workers' International Studies of Management \& Organization 47(4): 360-371.

Gilfillan, G. (2018) Characteristics and use of casual employees in Australia. Canberra: Parliamentary Library.

Goldin, C. (2014) 'A grand gender convergence: Its last chapter', American Economic Review 104: 1091-1119.

Goodin, R. E., Rice, J. M., Parpo, A. and Eriksson, L. (2008) Discretionary time: A new measure of freedom. Cambridge, UK: Cambridge University Press.

Gregg, M. (2011) Work's Intimacy. Cambridge, UK: Polity.

Harris, S. \& Krueger, A. (2015) A proposal for modernizing labor laws for twenty-first-century work: The 'independent worker'. The Hamilton Project: Discussion paper 10.

Hewitt, B., Craig, L. and Baxter, J. (2012) 'Family, work and wellbeing over the life course', Journal of Population Research 29: 289-292.

Hochschild, A. and Machung, A. (2003) The Second Shift. London: Penguin Books.

Hockey, J. (2009) 'The Life Course Anticipated: Gender and Chronologisation among Young People', Journal of Youth Studies 12: 227-241.

Nockolds, D (2017) Working sole parents and feminist perspectives on the intersection of gender and time, Journal of Sociology 53: 231-244.

Pocock, B., Skinner, N. \& Williams, P. (2012). Time Bomb: Work, rest and play in Australia today. Sydney: UNSW Press. 
Presser, H. B. (2005). Working in a 24/7 economy: Challenges for American families. New York: Russell Sage Foundation.

Price, R., McDonald P., Bailey, J. and Pini, B. (2011) ‘A majority experience: young people's encounters with the labour market', in pp. 1-17 R. Price, P. McDonald, J. Bailey and B. Pini (eds.) Young People and Work. Aldershot: Ashgate.

Strazdins, L., Clements, M.S., Korda, R.J., Broom, D.H. and D'Souza, R.M. (2006) 'Unsociable Work? Nonstandard Work Schedules, Family Relationships, and Children's Well-Being', Journal of Marriage and Family 68: 394-410.

Thompson, C.J. (1996) 'Caring Consumers: Gendered Consumption Meanings and the Juggling Lifestyle', Journal of Consumer Research 22: 388-407.

Venn, D. (2004) Work timing arrangements in Australia in the 1990s: Evidence from the Australian Time Use Survey. Melbourne: University of Melbourne (Doctoral dissertation).

Venn, D., Carey, G., Strazdins, L. and Burgess, J. (2016) 'What explains trends in Australian working time arrangements in the 2000s?', Labour \& Industry 26: 138-155.

Wajcman, J. (2014) Pressed for time: the acceleration of life in digital capitalism. Chicago: University of Chicago Press.

Yavorsky, J.E., Kamp Dush, C.M. and Schoppe-Sullivan, S.J. (2015) 'The production of inequality: The gender division of labor across the transition to parenthood', Journal of Marriage and Family 77: 662-679. 